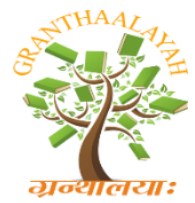

\author{
INTERNATIONAL JOURNAL OF RESEARCH \\ GRANTHAALAYAH \\ A knowledge Repository
}

Science

\title{
COMPARATIVE STUDY OF MACHINE LEARNING KNN, SVM, AND DECISION TREE ALGORITHM TO PREDICT STUDENT'S PERFORMANCE
}

\author{
Slamet Wiyono ${ }^{* 1}$, Taufiq Abidin ${ }^{2}$ \\ ${ }^{* 1,2}$ Politeknik Harapan Bersama, Jl. Mataram No. 9, Pesurungan Lor, Kota Tegal, Indonesia
}

\begin{abstract}
Students who are not-active will affect the number of students who graduate on time. Prevention of not-active students can be done by predicting student performance. The study was conducted by comparing the KNN, SVM, and Decision Tree algorithms to get the best predictive model. The model making process was carried out by steps; data collecting, pre-processing, model building, comparison of models, and evaluation. The results show that the SVM algorithm has the best accuracy in predicting with a precision value of $95 \%$. The Decision Tree algorithm has a prediction accuracy of $93 \%$ and the $\mathrm{KNN}$ algorithm has a prediction accuracy value of $92 \%$.
\end{abstract}

Keywords: Student Performance; KNN; SVM; Decision Tree.

Cite This Article: Slamet Wiyono, and Taufiq Abidin. (2019). "COMPARATIVE STUDY OF MACHINE LEARNING KNN, SVM, AND DECISION TREE ALGORITHM TO PREDICT STUDENT'S PERFORMANCE." International Journal of Research - Granthaalayah, 7(1), 190-196. https://doi.org/10.29121/granthaalayah.v7.i1.2019.1048.

\section{Introduction}

Improving the quality of education and accreditation of departments is always endeavored by every college department. Timeliness of graduating students is one of the elements for accreditation assessment [1]. The accreditation will be better if more students graduate on time. Students who are not-active will affect the number of students who graduate on time. Thus, the more students who graduate not on time will the lower the department's accreditation.

Prevention of not-active students can be done by predicting student performance. Several studies on student performance had been conducted. Some studies use Data Mining algorithm. Data Mining algorithm was used to perform student performance analysis system (SPAS) [2], to analyze student performance using clustering techniques [3], and to predict student performance (poor, average, good, and excellent) using educational data [4]. Other research by applying Decision Tree algorithms such as; predictions of drop-out students from college based on GPA [5], analysis to predictive the accuracy of 4-year studies of student [6]. Other research to predict student performance at the beginning of joining a course program [7], predicting student performance in 
distance higher education using active learning [8], predictions of student performance correlated with course activities [9], and predicting student performance using advanced learning analytics to compare features [10]. In addition to the Data Mining algorithm, using the Fuzzy method is also done to predict student performance. Fuzzy Support System method was used for evaluation of student performance in laboratory [11], and an application of fuzzy logic for evaluation of student academic performance [12].

Research by comparing several algorithms to get the best predictions has been done. Among had been done is; comparing Simple Logistic Classifier and SVM algorithms to predict athlete's win [13] at, comparative analysis between SVM and KNN classifier for EMG signal classification [14], compare KNN, SVM, and Random Forest algorithms for facial expression classification [15]. Comparative algorithm research for predicting student performance had also been carried out. Among them have been done are; look for classification algorithm that can be used to predict student performance [16], comparing Bayesian algorithm and Decision Tree [17], compare Apriori and K-Means algorithms [18], and compare Neural Network, SVM, and Decision Tree algorithms [19]. From some studies about student performance by comparing several algorithms, no one had compared the KNN, SVM, and Decision Tree algorithms in predicting student performance. The research that had been done aims to compare algorithms (KNN, SVM, and Decision Tree) to get the best model for predicting student performance.

\section{Methods}

This research had been done using several Machine Learning algorithms, namely KNN, SVM, and Random Forest. The tools used are R Studio. The library used in the R Studio is the Caret package. Machine Learning processing through several processes: data collecting, preprocessing, model building, comparison of models, and evaluation [20]. The research process is shown in Figure 1.

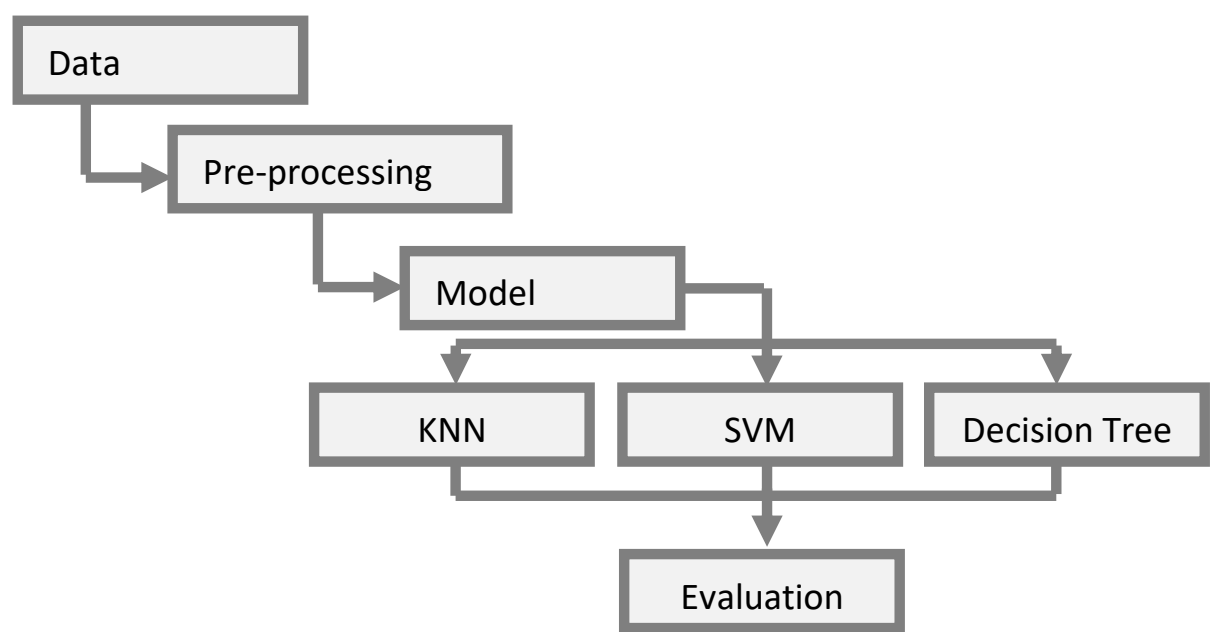

Figure 1: Step of the research process

Data collection by combining all data into one with the same attributes. The data used are: GP (grade point), GPA (grade point average), hometown, type of school, majors, parent's work, and student performance (aktive/non-active). Pre-processing is done to improve data before building a Machine Learning model. Problems in data are usually like different attributes, missing values, 
etc. Pre-processing is also done by spliting the data into training and testing. Training data is used to build models. The model that has been built is then tested using data testing to determine the accuracy of the prediction. The next step is to compare several models that have been built, namely the model of the KNN, SVM, and Decision Tree algorithm. The final step is to evaluate to determine the best algorithm for predicting student performance based on the model obtained.

\section{Results}

Student academic data of Informatics Engineering Department Politeknik Harapan Bersama are used in this paper. The dataset consists of 1530 rows and 7 attributes data. First 6 variables had used for predicting $7^{\text {th }}$ variable. Table 1 shows all the details of data.

Table 1: Detail of Dataset

\begin{tabular}{|c|c|c|c|}
\hline No & Feature Title & Variable Data Type & Feature Categorization \\
\hline 1 & GP & Continuous & $0-4$ \\
\hline 2 & GPA & Continuous & $0-4$ \\
\hline 3 & hometown & Categorical & $\begin{array}{l}\text { 1: city close from campus } \\
0 \text { : city near from campus }\end{array}$ \\
\hline 4 & type_of_school & Categorical & $\begin{array}{l}\text { 1: public school } \\
0: \text { private school }\end{array}$ \\
\hline 5 & major & Categorical & $\begin{array}{l}\text { 1: computer/informatics } \\
\text { 2: science major } \\
\text { 3: others }\end{array}$ \\
\hline 6 & parents_job & Categorical & $\begin{array}{l}\text { 1: civil servant } \\
\text { 2: employee } \\
\text { 3: entrepreneur } \\
\text { 4: farmer / fisherman } \\
\text { 5: others }\end{array}$ \\
\hline 7 & AKTIF & Categorical & $1=$ active, $0=$ non-active \\
\hline
\end{tabular}

GP (Grade Points) is the average score of learning outcomes every semester, 0 means the lowest score and 4 means the highest score. GPA (Grade Points Average) is the cumulative average point value of all semesters that have been passed, 0 means the lowest score and 4 means the highest score. Hometown is the hometown of students, 0 means student coming from a city that near from campus and 1 means student coming from a city far away from campus. Type of school is a type of high school, 0 means students come from private schools and 1 means students come from public schools. Major is majors when high school, 1 means students come from the computer/informatics department, 2 means students come from natural science majors, and 3 mean students come from other than both. Parents jobs are jobs from student parents, 1 means parents work as civil servants, 2 means as private employees, 3 mean as entrepreneurs, 4 means as farmers/fishermen, and 5 mean other than that. Actif is student performance, 0 means students are not active and 1 means students are active.

\section{Model Result}

Before the data is processed, the data set is split into two parts by a ratio of $75: 25$, which $75 \%$ to training and $25 \%$ to testing. Training data used to get model. Training data used were 1148 
samples, 6 predictor, and 2 classes, with cross-validation 10 fold and repeated 3 times. Output of training data is a model used for classification. The model that had been built is shown in Table 2 .

Table 2: Model Result

\begin{tabular}{|l|l|l|}
\hline Algorithm & Result & Accuracy \\
\hline KNN & $\mathrm{k}=5$ & $93.81 \%$ \\
\hline SVM & value C =1 & $95.09 \%$ \\
\hline Decision Tree & $\mathrm{cp}=0.6689113$ & $95.65 \%$ \\
\hline
\end{tabular}

The model was then tested used testing data to know how accurate that model. Table 3 show a matrix of the testing result for KNN algorithm, Table 4 is testing result for SVM algorithm, and Table 5 is testing result for Decision Tree algorithm.

\begin{tabular}{|c|c|c|}
\hline \multicolumn{3}{|c|}{ Table 3: Confusion Matrix for Knn } \\
\hline \multirow{2}{*}{ Prediction } & \multicolumn{2}{|c|}{ Reference } \\
\hline & active & non-active \\
\hline active & 308 & 21 \\
\hline non-active & 8 & 45 \\
\hline \multicolumn{3}{|c|}{ Table 4: Confusion Matrix for Svm } \\
\hline \multirow{2}{*}{ Prediction } & \multicolumn{2}{|c|}{ Reference } \\
\hline & active & non-active \\
\hline active & 311 & 13 \\
\hline non-active & 5 & 53 \\
\hline \multicolumn{3}{|c|}{ Table 5: Confusion Matrix for Decision $\mathrm{Tr}$} \\
\hline \multirow{2}{*}{ Prediction } & \multicolumn{2}{|c|}{ Reference } \\
\hline & active & non-active \\
\hline active & 308 & 18 \\
\hline non-active & 4 & 48 \\
\hline
\end{tabular}

\section{Classification Result}

Classification result is obtained from the model that has been tested. Table 6 shows the comparison of the testing result between KNN, SVM, and Decision Tree algorithm on the confusion matrix. Figure 5 shows the comparison accuracy between algorithm based on classes.

Table 6: Comparison of Confusion Matrix

\begin{tabular}{lllll}
\hline \hline \multicolumn{2}{l}{ Prediction } & KNN & SVM & Decision Tree \\
\hline \multirow{2}{*}{ Active } & TRUE & $94 \%$ & $96 \%$ & $94 \%$ \\
& FALSE & $6 \%$ & $4 \%$ & $6 \%$ \\
Non- & TRUE & $85 \%$ & $91 \%$ & $92 \%$ \\
Active & FALSE & $15 \%$ & $9 \%$ & $8 \%$
\end{tabular}




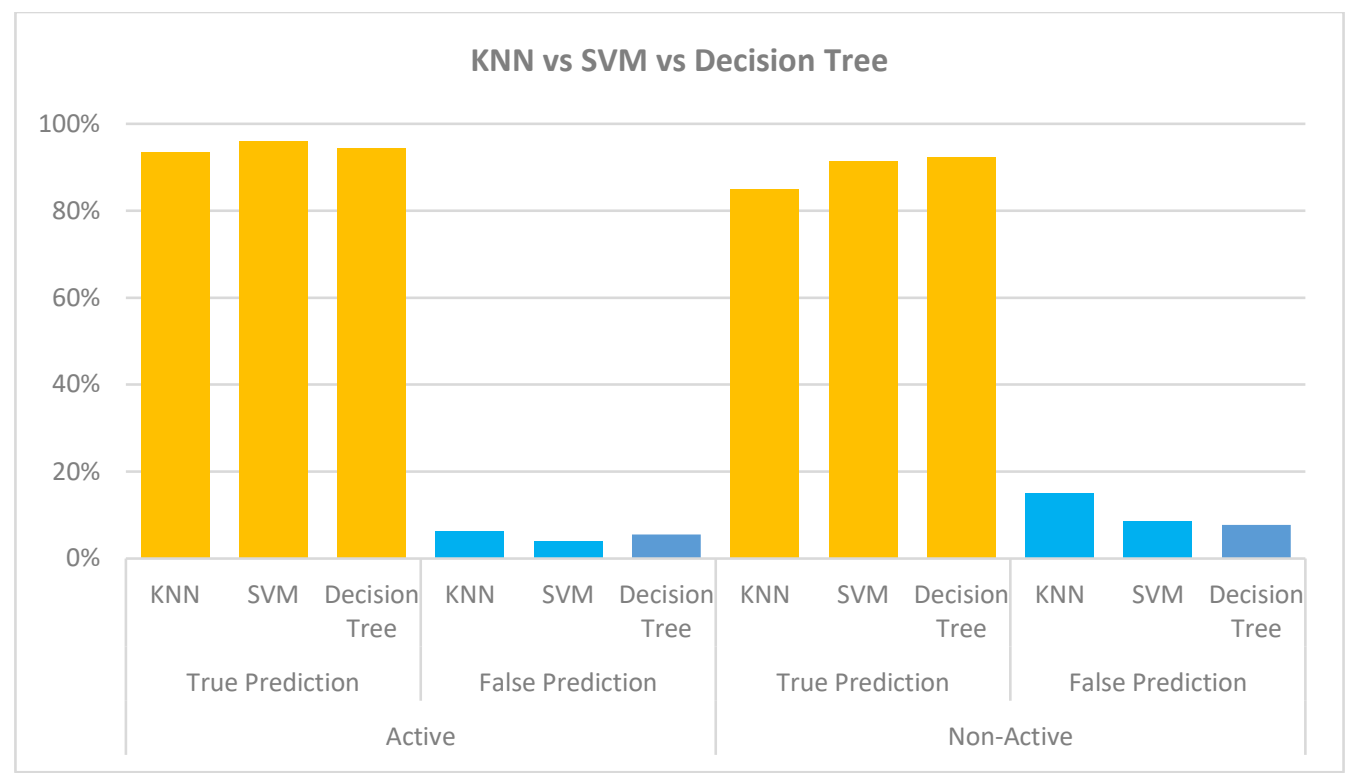

Figure 5: comparison of testing accuracy

The final result is a comparison of model classification to see which algorithm has the best accuracy. Table 7 shows the comparison of the classification model obtained, while Figure 6 shows the comparison graph of the classification accuracy.

Table 7: Classification Accuracy Comparison

\begin{tabular}{|l|l|l|}
\hline \multicolumn{3}{|c|}{ Accuracy } \\
\hline KNN & SVM & Decision Tree \\
\hline $92 \%$ & $95 \%$ & $93 \%$ \\
\hline
\end{tabular}

\section{Discussion}

The best model for $\mathrm{KNN}$ algorithm to predict student performance is $\mathrm{k}$ (kernel) $=5$ with accuracy $93.81 \%$, value C $=1$ for SVM algorithm with accuracy $95.09 \%$, and $\mathrm{cp}=0.6689113$ for Decision Tree algorithm with $95.65 \%$ accuracy. The comparison of the three algorithms shows that the best accuracy is the Decision Tree algorithm. This model has not been tested yet. After testing, it turns out that the SVM model can predict better than the KNN algorithm and Decision Tree. It can be seen that the SVM algorithm can predict exactly 311 active students and 53 non-active students, while the Decision Tree algorithm can only predict exactly 308 active students and 48 non-active students, and the KNN algorithm only predicts exactly 308 active students and 45 non-active students. If not testing the model, the Decision Tree is the best predictive accuracy model compared to SVM and KNN. Whereas if the model testing is done, SVM algorithm is the best accuracy model compared to Decisioan Tree and KNN.

Comparison with marix confusion shows different things from the results of previous comparisons. SVM algorithm has the best accuracy to predict active students (96\%) compared to KNN (92\%) and Decision Tree (92\%). However, the Decision Tree algorithm has the best accuracy for predict non-active students (92\%) compared to SVM (91\%) and KNN (85\%). Although algorithm decision tree has the best accuracy in predicting non-active students, but only $1 \%$ difference from SVM 
algorithm. While for predicting the accuracy of active students, SVM has a 4\% difference from Decision Tree and KNN. It could be said that the SVM algorithm still occupies the best position compared to Decision Tree and KNN. This is corroborated after the overall accuracy calculation is performed, it is found that SVM has the best classification accuracy of $95 \%$ while the Decision Tree has 93\% accuracy and KNN has 92\% accuracy. Thus, the best algorithm for predicting student performance is by using the SVM algorithm.

\section{Conclusions}

KNN algorithm can predict student performance well with $\mathrm{k}=5$. The best model of SVM algorithm to predict student's performance is by using the value of $\mathrm{C}=1$. Whereas if using the Decision Tree algorithm, the best predictions if using the model $\mathrm{cp}=0.6689113$. Comparison of three algorithm machine learning (KNN, SVM, and Decision Tree) shows that SVM has the best accuracy (95\%) compared to Decision Tree (93\%) and KNN (92\%) in predicting student performance.

\section{Acknowledgments}

This research supported by Ministry of Research, Technology and Higher Education (RISTEKDIKTI) Indonesia.

\section{References}

[1] BAN-PT, Buku I Naskah Akademik Akreditasi Institusi Perguruan Tinggi. Jakarta: BAN-PT, 2011.

[2] C. L. Sa, D. H. b. A. Ibrahim, E. D. Hossain, and M. bin Hossin, "Student performance analysis system (SPAS)," in The 5th International Conference on Information and Communication Technology for The Muslim World (ICT4M), 2014, pp. 1-6.

[3] I. Singh, A. S. Sabitha, and A. Bansal, "Student performance analysis using clustering algorithm," in 2016 6th International Conference - Cloud System and Big Data Engineering (Confluence), 2016, pp. 294-299.

[4] T. Devasia, T. P. Vinushree, and V. Hegde, "Prediction of students performance using Educational Data Mining," in 2016 International Conference on Data Mining and Advanced Computing (SAPIENCE), 2016, pp. 91-95.

[5] M. N. Quadri and N. V. Kalyankar, "Drop Out Feature of Student Data for Academic Performance Using Decision Tree Techniques," Glob. J. Comput. Sci. Technol., vol. 10, no. 2, pp. 2-5, 2010.

[6] R. Asif, A. Merceron, S. A. Ali, and N. G. Haider, "Analyzing undergraduate students' performance using educational data mining," Comput. Educ., vol. 113, pp. 177-194, 2017.

[7] A. Vihavainen, "Predicting Students' Performance in an Introductory Programming Course Using Data from Students' Own Programming Process," in 2013 IEEE 13th International Conference on Advanced Learning Technologies, 2013, pp. 498-499.

[8] G. Kostopoulos and A. Lipitakis, "Predicting Student Performance in Distance Higher Education Using Active Learning," Int. Conf. Eng. Appl. Neural Networks, vol. 744, no. Dm, pp. 75-86, 2017.

[9] R. Conijn, A. Van den Beemt, and P. Cuijpers, "Predicting student performance in a blended MOOC," J. Comput. Assist. Learn., no. March, pp. 1-14, 2018.

[10] A. Daud, N. R. Aljohani, R. A. Abbasi, M. D. Lytras, F. Abbas, and J. S. Alowibdi, "Predicting Student Performance using Advanced Learning Analytics," Proc. 26th Int. Conf. World Wide Web Companion, pp. 415-421, 2017. 
[11] Z. Y1ldız and A. F. Baba, "Evaluation of student performance in laboratory applications using fuzzy decision support system model," in 2014 IEEE Global Engineering Education Conference (EDUCON), 2014, pp. 1023-1027.

[12] P. Nagar, "Application of Fuzzy Logic for Evaluation of Academic Performance of Students of Computer,” Iran. Conf. Fuzzy Syst., vol. 3, no. X, pp. 260-267, 2013.

[13] E. Rainarli and A. Romadhan, "Perbandingan Simple Logistic Classifier dengan Support Vector Machine dalam Memprediksi Kemenangan Atlet," J. Inf. Syst. Eng. Bus. Intell., vol. 3, no. 2, p. 87, 2017.

[14] Y. Paul, V. Goyal, and R. A. Jaswal, "Comparative analysis between SVM \& KNN classifier for EMG signal classification on elementary time domain features," 4th IEEE Int. Conf. Signal Process. Comput. Control. ISPCC 2017, vol. 2017-Janua, pp. 169-175, 2018.

[15] R. A. Nugraheni and K. Mutijarsa, "Comparative Analysis of Machine Learning KNN, SVM, and Random Forests Algorithm for Facial Expression Classification," in ISEMANTIC, 2016, pp. 163168.

[16] V. Patil, S. Suryawanshi, M. Saner, and V. Patil, "Student Performance Prediction Using Classification Data Mining Techniques," Int. J. Res. Emerg. Sci. Technol., vol. 4, no. 444, pp. 15$18,2017$.

[17] A. U. Khasanah and Harwati, "A Comparative Study to Predict Student's Performance Using Educational Data Mining Techniques," IOP Conf. Ser. Mater. Sci. Eng., vol. 215, p. 012036, Jun. 2017.

[18] G. S. Gowri, R. Thulasiram, and M. A. Baburao, "Educational Data Mining Application for Estimating Students Performance in Weka Environment," IOP Conf. Ser. Mater. Sci. Eng., vol. 263, no. 3, 2017.

[19] M. Ciolacu, A. F. Tehrani, R. Beer, and H. Popp, "Education 4. 0 - Fostering Student' s Performance with Machine Learning Methods," in SIITME, 2017.

[20] B. Lantz, Machine Learning with R, 2nd ed. Birmingham-Mumbai: Packt Publishing Ltd., 2015.

*Corresponding author.

E-mail address: slamet2wiyono@ gmail.com/ N3k4ther.otr@ gmail.com 